\title{
KEANEKARAGAMAN SERANGGA PERMUKAAN TANAH DI KAWASAN BUKIT GATAN KABUPATEN MUSI RAWAS
}

Dina Setiawati ${ }^{1}$, Yunita Wardianti ${ }^{2}$, Mareta Widiya ${ }^{3}$

1,2,3STKIP PGRI Lubuklinggau, Jl. Mayor Toha Kel Air Kuti Kota Lubuklinggau 31626, Indonesia *Corresponding author email : yunita.wardianti13@gmail.com

\section{ABS T RACT}

This study aims to determine the diversity of soil surface insects, in the Bukit Gatan area, Musi Rawas Regency. This research is a qualitative descriptive study using a pitfall trap and using a random sampling method. The results showed that the types of ground surface insects contained 3 orders, 5 families and 10 species.The results of the analysis of the ecological index of soil surface insects in the Gatan hill area, Musi Rawas Regency, namely the diversity index ( $\left.\mathrm{H}^{\prime}\right) 1.241$ in the low category, Evennes index (E') 0.64 in the medium category, and the dominance index (C) 0.277 in the medium category.The abiotic factors in the Bukit Gatan area, Musi Rawas Regency at the research site are the average air temperature $29^{\circ} \mathrm{C}$, average soil $\mathrm{pH} 6.5$, and average soil moisture $85.3 \%$.Diversity of soil surface insects in the Bukit Gatan area, Musi Rawas Regency is in the low category.

Keywords: Diversity, Soil Insect, Bukit Gatan

\section{PENDAHULUAN}

Indonesia terletak di kawasan tropik yang mempunyai iklim yang stabil sehingga memungkinkan bagi berbagai macam flora dan fauna hidup dan berkembang biak (Siregar et al., 2009). Indonesia memiliki keanekaragaman hayati yang tinggi, 10\% flora berbunga, 12\% mamalia, 17\% jenis burung, 25\% jenis ikan dan 15\% serangga, keanekaragaman dunia ada di Indonesia dengan kekayaan jenis yang tinggi tersebut membuat Indonesia disebut dengan megabioversity Indonesia memiliki sepesies serangga sekitar 250.000 spesies dari 751.000 spesies (Haneda \& Sirait, 2012; Rahayuningsih et al., 2012).

Serangga permukaan tanah merupakan kelompok yang sering dilupakan bahkan serangga permukaan tanah sering disebut sebagai parasit pada organisme lain (Rachmasari et al, 2016). Padahal kelompok ini mempunyai potensi yang tidak ternilai, terutama membantu dalam perombakan bahan organik tanah (Marheni et al., 2017). Kehidupan serangga permukaan tanah tergantung pada tempat hidupnya dan keberadaan hewan tanah ditentukan oleh situasi tempat tinggalnya tersebut serta tergantung pada faktor lingkungan (Pratiwi et al., 2018).

Serangga permukaan tanah memiliki peranan penting terhadap keberlangsungan kehidupan vegetasi diatasnya dan berperan penting dalam ekosistem tanah (Nuraeni \& Mangesu, 2017). Serangga memiliki nilai penting yaitu nilai ekologi, endemisme, konservasi, estetika dan pendidikan serta ekonomi (Rachmasari et al., 2016). Serangga merupakan bagian dari keanekaragaman hayati dengan potensi manfaat terbesar yang harus dijaga kelestariannya dari kepunahan maupun penurunan keanekaragaman jenisnya (Andriani et al., 2017).

Keanekaragaman serangga tanah berbeda disetiap habitat (Zulkarnain et al., 2018). Hal tersebut dikarenakan serangga berdasarkan tempat hidupnya ada yang 
hidup pada lapisan tumbuh-tumbuhan, contohnya ordo Plecoptera (Fauziah, 2019). Kemudian serangga yang hidup pada lapisan organik tanah misalnya, ordo Dermatera dan serangga yang hidup pada lapisan mineral tanah misalnya, ordo Protura (Suin, 2012). Serangga permukaan tanah dapat dijumpai hampir seluruh daerah, selain itu serangga permukaan tanah juga memiliki kemampuan untuk beradaptasi dengan ekosistem tempat tinggalnya sehingga hal inilah yang mampu menyebabkan serangga bersifat resistensi terhadap insektisida (Fakhrah, 2016). Tempat tinggal serangga permukaan tanah banyak dijumpai di perbukitan salah satunya yaitu Bukit Gatan yang berada Kabupaten Musi Rawas, Provinsi Sumatra Selatan, namum jenisnya belum terdata sehingga sangat baik jika dilakukan kegiatan ilmiah dengan tema keanekaragaman serangga permukaan tanah di kawasan Bukit Gatan Kabupaten Musi Rawas.

\section{METODE}

Jenis penelitian ini yaitu penelitian deskriptif kuantitatif, metode pengambilan data menggunakan metode purposive sampling yaitu metode yang dilakukan secara teratur dengan bantuan pitfall trapserta menggunakan transek yang diletakan di setiap stasiun. Adapun prosedur penelitian dengan melakukan observasi, penentuan lokasi, persiapan alat dan bahan, serta pengambilan data. Alat yang digunakan dalam penelitian yaitu, triplek, paku, gelas plastik, bambu, tali raffia, mangkuk plastik, botol plastik, baskom, lup, pinset, saringan,soil tester, hygrometer. Bahan yang digunakan dalam peneltian ini adalah deterjen, gula, air dan alkohol 70\%.

Pada penelitian ini alat yang digunakan untuk menjebak serangga permukaan tanah adalah gelas plastik berdiameter $8,5 \mathrm{~cm}$ setinggi $10 \mathrm{~cm}$, dan di isi $1 / 4$ larutan detergen dan gula. Selanjutnya gelas jebakan diletakan di lubang sedalam $10 \mathrm{~cm}$, dengan permukaan gelas plastik tersebut sejajar dengan permukaan tanah, pada bagian atas gelas plastik jebakan ditutup menggunakan dengan triplek yang diberi penyanggah setinggi $10 \mathrm{~cm}$ dari permukaan tanah agar serangga bisa masuk kedalam jebakan dan menghindari masuknya air hujan kedalam jebakan, perangkap ini dibiarkan selama 24 jam (Rezatinur et al., 2016). Serangga permukaan tanah yang terjebak di dalam pitfall trap dituang ke saringan dan dicuci menggunakan air, kemudian serangga permukaan tanah tersebut diawetkan menggunakan alkohol $70 \%$ dan diamati dengan menggunakan lup (Gesriantuti et al., 2016). Data yang didapat kemudian dianalisis indeks keanekaragaman dengan menggunakan rumus ShannonWiener (Ismani et al., 2015).

\section{HASIL DAN PEMBAHASAN}

Berdasarkan hasil penelitian ditemukan 10 spesies serangga yang tergolong kedalam 5 famili. Pada stasiun I ditemukan sebanyak 953 individu, stasiun II sebanyak 483 individu dan stasiun III sebanyak 384 individu. Serangga yang terjebak akan dikelompokkan kedalam ordo, family, genus dan spesies. Serangga permukaan tanah yang telah ditemukan tergolong dari ordo Hymenoptera, ordo Orthoptera, dan ordo Coleoptera. Data serangga permukaan tanah yang telah ditemukan Bukit Gatan Kabupaten Musi Rawas di tiga stasiun dapat dilihat dalam Tabel 1.

Hasil analisis indeks ekologi serangga permukaan tanah di kawasan bukit Gatan Kabupaten Musi Rawas (Tabel 2) yaitu indeks keanekaragaman ( $\left.\mathrm{H}^{\prime}\right)$ 1,241 dengan kategori rendah, indeks keseragaman ( $\left.E^{\prime}\right)$ 0,64 dengan kategori sedang, dan indeks dominansi (C) 0,277 dengan kategori sedang. Jumlah serangga permukaan tanah yang paling banyak ditemukan adalah ordo Hymenoptera dengan 6 Jenis spesies, ordo 
Orthoptera dengan 3 jenis spesies, ordo Coleoptera dengan 1 jenis spesies. Pada stasiun 1 terdapat 3 Ordo dengan 3 Family dengan 6 genus dan 8 spesies.

Tabel 1. Serangga Permukaan Tanah di Bukit Gatan Kabupaten Musi Rawas.

\begin{tabular}{|c|c|c|c|c|c|c|}
\hline \multirow{2}{*}{ NO } & \multirow{2}{*}{ Famili } & \multirow{2}{*}{ Spesies } & \multicolumn{3}{|c|}{ Stasiun } & \multirow{2}{*}{ Total } \\
\hline & & & I & II & III & \\
\hline 1 & Formicidae & Dolichoderus bituberculatus & 66 & 44 & 32 & 142 \\
\hline 2 & Formicidae & Camponotus tavlori & 377 & 236 & - & 613 \\
\hline 3 & Formicidae & Oechophylla smaragdina & 50 & - & 25 & 75 \\
\hline 4 & Formicidae & Monomorium minimum & 378 & 154 & 242 & 774 \\
\hline 5 & Acrididae & Phlaeoba sp. & - & 9 & - & 9 \\
\hline 6 & Gryllidae & Gryllus bimaculatus & - & 5 & 4 & 9 \\
\hline 7 & Formicidae & Camponotus pensylvanicus & 44 & 21 & 20 & 85 \\
\hline 8 & Carabidae & Chlaenius sp. & 4 & - & - & 4 \\
\hline 9 & Blattidae & Blattella sp. & 2 & - & - & 2 \\
\hline 10 & Formicidae & Camponotus sericeus & 32 & 14 & 25 & 71 \\
\hline \multicolumn{3}{|c|}{$\begin{array}{l}\text { Jumlah Total Individu } \\
\end{array}$} & 953 & 438 & 348 & 1.784 \\
\hline
\end{tabular}

Tabel 2. Nilai Indeks Ekologi

\begin{tabular}{clcc}
\hline No & \multicolumn{1}{c}{ Indeks } & Nilai & Kategori \\
\hline 1 & Keanekaragaman $\left(H^{\prime}\right)$ & 1,241 & Rendah \\
2 & Keseragaman $\left(E^{\prime}\right)$ & 0,64 & Sedang \\
3 & Dominansi $(C)$ & 0,277 & Sedang \\
\hline
\end{tabular}

Spesies yang ditemukan yaitu Dolichoderus bituberculatus, Camponotus tavlori, Oecophylla smaragdina, Monomorium minimum, Camponotus pennsylvanicus, Chlaenius sp., dan Blattella sp. Pada stasiun II terdapat 2 ordo dengan 3 family dengan 6 genus dan 7 Spesies. Spesies tersebut yaitu Dolichoderus bituberculatus, Camponotus tavlori, Monomorium minimum, Phlaeoba sp., Gryllus bimaculatus, Camponotus pennsylvanicus, dan Camponotus sericeus.Pada stasiun III terdapat 2 ordo dengan 2 family dengan 5 Genus dan 6 spesies, spesies tersebut yaitu Dolichoderus bituberculatus, Oecophylla smaragdina, Monomorium minimum, Gryllus bimaculatus, Camponotus pennsylvanicus, dan Camponotus sericeus.

Populasi yang paling banyak terdapat pada stasiun 1 dengan jumlah 953 ekor populasi dan yang paling banyak yaitu spesies Monomorium minimum dengan jumlah 378 ekor yang terperangkap ke dalam pitfall trappada stasiun 1. Selanjutnya spesies Camponotus tavlori dengan jumlah 377 ekor, pada spesies Oechophylla smaragdina 50 ekor, pada spesies Dolichoderus bituberculatusdengan jumlah 66 ekor, pada spesies Camponotus pennsylvanicus dengan jumlah 44 ekor, pada spesies Chlaenius sp. dengan jumlah 4 ekor, pada spesies Camponotus sericeus dengan jumlah 32 ekor, dan yang paling sedikit populasi spesies Blattella sp. dengan jumlah 2 ekor.

Populasi spesies pada stasiun II yaitu dengan jumlah seluruhnya 438 ekor, dan yang paling banyak terperangkap kedalam pitfall trap adalah spesies Camponotus tavlori dengan jumlah 236 ekor,selanjutnya pada spesies Dolichoderus bituberculatusd engan jumlah 44 ekor, pada spesiesMonomorium minimum dengan jumlah 154 ekor, pada spesies Phlaeoba sp dengan jumlah 9 ekor, pada spesies Camponotus pennsylvanicus dengan jumlah 21 ekor, pada spesies Camponotus sericeus dengan jumlah 14 ekor,dan populasi yang paling sedikit adalah spesiesGryllus bimaculatus dengan jumlah 5 ekor. 
Pada stasiun III jumlah populasi spesies seluruhnya yaitu 348 ekor, yang paling banyak terperangkap kedalam pitfall trap yaitu spesies Monomorium minimum dengan jumlah 242 ekor, selanjutnya pada spesies Dolichoderus bituberculatus dengan jumlah 32 ekor, pada spesies Oecophylla smaragdina dengan jumlah 25 ekor, Pada spesies Camponotus pennsylvanicus dengan jumlah 20 ekor, dan populasi yang paling sedikit adalah spesies Gryllus bimaculatus dengan jumlah 4 ekor.

Berdasarkan ketiga stasiun tersebut stasiun 1 yang paling banyak terperangkap serangga permukaan tanahnya ke dalam jebakan pitfall trap yaitu spesies Monomorium minimum yang termasuk kedalam ordo Hymenoptera family formicidae karena hidupnya yang bersosial dan berkoloni. Hal ini dikuatkan oleh Kinasih (2017) menyatakan bahwa family Formicidae adalah serangga yang paling umum dan jumlah sukunya yang paling banyak beraktivitas di tanah. Family Formicidae ini hidupnya berkoloni serta dapat mencapai 70\% dari populasi serangga permukaan tanah yang ada, sehingga family ini dapat dijumpai dalam jumlah banyak. Serangga jenis ini banyak ditemukan ditempat yang lembab, teduh, serasah, sampah dan kayu lapuk yang menyebabkan adanya sumber makanan untuk serangga permukaan tanah, hingga mampu mendukung pertumbuhan serangga permukaaan tanah. Serangga permukaan tanah mempunyai potensi yang tidak ternilai terutama dalam membantu perombakan bahan organik tanah, juga menjadi salah satu makhluk penyeimbang lingkungan.

Stasiun III merupakan stasiun yang paling sedikit terperangkap serangga permukaan tanahnya serta paling sedikit spesies yang terperangkap kedalam jebakan pitfall trapyaitu spesies Blattella sp. Ini disebabkan karena pada stasiun III merupakan kawasan wisata air terjun yang hampir setiap harinya dikunjungi oleh masyarakat, masyarakat yang berkunjung sering membuang sampah sembarangan disekitar kawasan air terjun yang menyebabkan terganggunya aktivitas serangga permukaan tanah. Keberadaan serangga permukaan tanah juga tergantung pada ketersediaan energi serta sumber makanan yang ada agar dapat melangsungkan hidup mereka. Serangga permukaan tanah itu bersifat mobile (dapat bergerak), Jadi sedikitnya jumlah suatu spesies serangga permukaan tanah yang ditemukan itu dikarenakanserangga tersebut berpindah tempat yang diakibatkan kondisi lingkungannya tidak baik ataupun terganggu. Seacara teoritis mahluk hidup akan berpindah tempat utuk sementara waktu dari suatu lingkungan ke lingkungan lainnya, ketika terjadinya gangguan, ancaman atau perubahan lingkungan sementara (Gesriantuti et al., 2016).

Tabel 3.Pengukuran Suhu Udara, pH Tanah dan Kelembaban Tanah

\begin{tabular}{llcccc}
\hline \multirow{2}{*}{ No } & \multicolumn{1}{c}{ Parameter } & $\begin{array}{c}\text { Nilai } \\
\mathbf{1}\end{array}$ & $\begin{array}{c}\text { Stasiun } \\
\text { II }\end{array}$ & $\begin{array}{c}\text { Stasiun } \\
\text { III }\end{array}$ & $\begin{array}{c}\text { Rata - } \\
\text { rata }\end{array}$ \\
\hline 1. & Suhu $\left({ }^{\circ} \mathrm{C}\right)$ & $28,6 \mathrm{C}$ & $29,6 \mathrm{C}$ & $29 \mathrm{C}$ & $29 \mathrm{C}$ \\
2. & pH Tanah & 6,6 & 6,5 & 6,5 & 6,5 \\
3. & Kelembaban Tanah $(\%)$ & 90 & 80,6 & 85,3 & 85,3 \\
\hline
\end{tabular}

Serangga permukaan tanah memiliki hubungan yang sangat erat dengan faktor abiotik, karena faktor abiotik menunjang keberadaan serangga permukaan tanah yang ada didalam kepadatan populasi. Pengukuran faktor abiotik dapat diketahui kepadatan populasi serangga permukaan tanah yang akan diteliti (Suin, 2012). Faktor abiotik yang diukur seperti $\mathrm{pH}$ tanah, kelembaban tanah, dan suhu udara.Suhu dilokasi penelitian di Kawasan Bukit Gatan Kabupaten Musi Rawas dapat dilihat pada Tabel 3, pada stasiun 1 memiliki rata-rata suhu $28,6^{\circ} \mathrm{C}$, pada stasiun II memiliki rata-rata suhu 
$29,6^{\circ} \mathrm{C}$, dan stasiun III memiliki rata-rata suhu $29^{\circ} \mathrm{C}$. Suhu adalah faktor pembatas dalam pertumbuhan dan perkembangan serangga permukaan tanah. Umumnya suhu serangga permukaan tanah yang efektif yaitu suhu minimum $15^{\circ} \mathrm{C}$, suhu optimum bagi perkembangan dan kelangsungan hidup serangga permukaan tanah yaitu berkisar $25^{\circ} \mathrm{Cdan}$ suhu maksimum $45^{\circ} \mathrm{C}$ (Rizali et al., 2012). Suhu pada ketiga lokasi penelitian menunjukkan bahwa suhu udara dilokasi penelitian adalah suhu optimum bagi perkembangan serangga permukaan tanah.

$\mathrm{pH}$ tanah berpengaruh bagi kehidupan serta kegiatan serangga permukaan tanah. Serangga permukaan tanah sangat sensistif terhadap $\mathrm{pH}$ tanah, karena $\mathrm{pH}$ tanah adalah salah satu pembatas. Hasil pengukuran di lokasi penelitian didapat bahwa $\mathrm{pH}$ tanah rata-rata 6,5. $\mathrm{pH}$ tersebut termasuk netral karena $\mathrm{pH}$ tanah yang baik apabila berada di kisaran 6,5 - 7,5 yang memungkinkan untuk tersedianya berbagai unsur kimiawi yang seimbang (Rizali et al., 2012).

Kelembaban tanah pada ketiga lokasi penelitian di Kawasan Bukit Gatan Kabupaten Musi Rawas rata-rata 85,3\%. Kelembaban tanah erat hubungannya dengan populasi serangga permukaan tanah, karena apabila tanah yang kering dapat menyebabkan serangga permukaaan tanah dehiderasi (Rizali et al., 2012). Oleh karena itu, kelembaban tanah sangat berperan penting dalam menentukan keanekaragaman serangga permukaan tanah di lokasi penelitian tersebut.

\section{SIMPULAN}

Hasil analisis indeks ekologi serangga permukaan tanah di kawasan bukit Gatan Kabupaten Musi Rawas yaitu indeks keanekaragaman ( $\left.\mathrm{H}^{\prime}\right)$ 1,241 dengan kategori rendah, indeks keseragaman ( $E^{\prime}$ ) 0,64 dengan kategori sedang, dan indeks dominansi (C)0,277 dengan kategori sedang. Faktor abiotik di Kawasan Bukit Gatan Kabupaten Musi Rawas di lokasi penelitian yaitu suhu udara rata - rata $29{ }^{\circ} \mathrm{C} \mathrm{pH}$ tanah rata-rata 6,5, dan kelembaban tanah rata-rata $85,3 \%$.

\section{REFERENSI}

Andriani, D, M., Setianingsih, M., Susilo., Metiani., \& Darma, A, P. (2017), Keanekaragaman dan Pola Penyebaran Insekta Permukaan Tanah di Resort Cisarua Taman Nasional Gunung Gede Pangrango Jawa Barat. Jurnal Pendidikan Biologi dan Biosains,1(1), 24-30.

Fakhrah. (2016). Inventarisasi Insekta Permukaan Tanah Di Gampong Krueng Simpo Kecamatan Juli Kabupaten Bireuen. Jurnal Pendidikan Almuslim, 4 (1): 48 -52.

Fauziah, N. (2015). Efektivitas Penggunaan Alat Bantu Reaksi Gerakan Tangan Bagi Kaum Disabilitas.Bandung: Universitas Pendidikan Indonesia.

Gesriantuti, N., Badrun, Y., \& Lestari, O. (2016).Keanekaragaman dan Peranan Serangga Permukaan Tanah Pada Ekosistem Mangrove di Desa Sungai Rawa, Kecamatan Sungai Apit, Kabupaten Siak, Riau. Prosiding 1th Celscitech ,Riau: UMRI.1(1), 4450.

Haneda \& Sirait, B, A. (2012). Keanekaragaman Fauna Tanah dan Peranannya terhadap LajuDekomposisi Serasah Kelapa Sawit (Elaeis guineensis Jacq).Jurnal Silvikultur Tropika, 3(3), 161-167.

Ismani, L., Lailati, M., \& Rustandi, S. D. 2015. Analisis komposisi dan keanekaragaman tumbuhan di Gunung Dempo, Sumatera Selatan. Prosiding Seminar Nasional Biodiversitas Indonesia. 1 (6) : 13-18. 
Kinasih, I., Tri, C., \& Zhia, R. A. (2017). Perbedaan Keanekaragaman dan Komposisi dari Serangga Permukaan Tanah Pada Beberapa Zonasi Di Hutan Gunung Geulis Sumedang. Jurnal Eksperimen, 03(1), 1-10.

Marheni, Y, B., Rahardjanto, A., \& Hindun, I. (2017).Keanekaragaman Serangga Tanah dan Peranannya Di Ekosistem Hutan Hujan Tropis Ranu Pani.Prosiding Seminar Nasional III. Malang: Universitas Muhamadiah Malang. 254-258.

Nuraeni S., \& Mangesu N. (2017). Keanekaragaman Serangga Permukaan Tanah Pada Hutan Tanaman Dan Hutan Alam Di Hutan Pendidikan Universitas Hasanuddin. Jurnal Satria Seri Ilmu Pengetahuan Alam, 32 : 62 - 69.

Pratiwi, D, I., Arisandy, D, A., \& Febrianti, Y. (2018).Keanekaragaman Serangga Permukaan Tanah Di Kebun Kopi Desa Belumai Kecamatan Padang Ulang Tanding Kabupaten Rejang Lebong.Lubuklinggau : STKIP-PGRI Lubuklinggau.

Rachmasari, O.D., Prihanta, W., Susetyarini, R.E. (2016). Keanekaragaman Serangga Permukaan Tanah Di Arboretum Sumber Brantas Baru-Malang Sebagai Dasar Pembuatan Sumber Belajar Flipchart. Jurnal Pendidikan Biologi Indonesia, 2(2), 188-197.

Rahayuningsih, M., Oqtafiana, R., \& Priyono, B. (2012).Keanekaragaman Jenis Kupukupu SuperFamili Papilionoidae di Dukuh Banyuwindu Desa Limbangan Kecamatan Limbangan Kabupaten Kendal. Jurnal MIPA,35(1), 11-20.

Rezatinur, W., Ilma, N., Meryanti.,\& Rosita, (2016). Populasi Serangga Permukaan Tanah di Urnal Pada Biotop Terededah dan Ternaung di Gampong Rinon Pulo Breuh Kecamatan Pulo Aceh Kabupaten Aceh Besar.Prosiding Seminar Nasional Biotik.

Rizali, A., Buchori, D. Triwidodo, H. (2012). Keanekaragaman Serangga pada lahan persawahan - tepian hutan: indicator untuk kondisi lingkungan. Jurnal hayati. 9(2), 41-48.

Siregar, Zulianti \& Amelia.(2009). Serangga Berguna Pertanian. Medan: USU Press.

Suin, N. M. (2012). Ekologi Hewan Tanah. Jakarta: Bumi Aksara.

Zulkarnain, Arifin, Z., \& Riyanto. (2018). Inventarisasi Serangga Tanah di Lahan Bekas Kebakaran Desa Tanjung Batu Kecamatan Tanjung Batu Kabupaten Ogan Ilir dan Sumbangannya Pada Pembelajaran Biologi SMA. Jurnal Pembelajaran Biologi, 5(1), 2-10. 